\title{
NATURAL SELECTION IN THE INDUSTRIAL MELANIC PSOCID MESOPSOCUS UNIPUNCTATUS (MÜLL.) (INSECTA: PSOCOPTERA) IN NORTHERN ENGLAND
}

\author{
C. POPESCU* \\ Department of Zoology, University of Leeds
}

Received 20.xii.77

\begin{abstract}
Summary
The nature of the selective forces operating on $M$. unipunctatus abdominal colour morphs are examined using two forms of multiple regression analysis, one based upon 11 environmental variables measured at 42 localities in northern England, the other on five principal components generated from them. Results point to the importance particularly of visual selection by predators for crypsis but also of climate.

Aviary and mark release recapture experiments, although not statistically significant, provide direct evidence that birds predate $M$. unipunctatus with regard to their cryptic efficiency. In both experiments more dark than light insects were taken on lichen-covered rural branches while the reverse, i.e. more light than dark insects taken on lichen-free urban branches, was evident in field experiments only.

Comparisons of morph developmental rate in the field suggest that climatic selection may operate differentially upon the two morphs since dark adult females are heavier than light ones during the pre-oviposition period at the four localities sampled in Yorkshire.

The abdominal colour polymorphism appears to be stable in Yorkshire at present and two systems by which it may be maintained are discussed.
\end{abstract}

\section{INTRODUCTION}

Mesopsocus unipunctatus is common and widely distributed in the north of England on the bark of many tree species where it feeds on the mixture of Pleurococcus and honey-dew moulds (Broadhead, 1958). In Yorkshire, this insect displays a colour dimorphism such that the light form is common and highly cryptic in rural areas on lichen-covered bark, while the dark, industrial melanic, form is common and highly cryptic in urban areas on dark bark without epiphytic growth. This dimorphism is obvious in late instar nymphs and apterous females, which live their entire lives exposed on the bark of trees; the situation is less clear-cut in adult males, however, which are winged and cannot rely on body colour for concealment. Genetic crosses indicate that the dark, melanic form is inherited as a Mendelian dominant and that two separate alleles, linked on the same chromosome, control the colours of head-thorax and abdomen respectively (Popescu, Broadhead and Shorrocks, 1978).

In this paper, the nature of the selective forces maintaining the abdominal colour dimorphism in adult females of $M$. unipunctatus is investigated by relating morph frequency to environmental variables using multivariate techniques and the intensity of the important forces, namely visual predation

* Present address: School of Biological Sciences, Botany Building, The University of Sydney, N.S.W., Australia 2006. 
and temperature selection, is examined by aviary and mark release recapture experiments and by comparisons of morph developmental rates.

\section{RELATIONSHIPS WITH ENVIRONMENTAL VARIABLES}

To indicate some of the factors responsible for maintaining the colour dimorphism, the geographic variation of melanic frequency in Yorkshire (based on collections made at 42 localities along a broad northerly transect from the industrial south to the rural north of Yorkshire, Popescu et al., 1978) was related to 11 environmental variables by multiple regression and principal component analysis. These variables, measured at each of the 42 collection sites, are related either to the degree of local air pollution, the cryptic value of the bark, or to climate.

\section{(i) Measurement of the variables}

Mean annual levels $\left(\mu \mathrm{g} / \mathrm{m}^{3}\right)$ of the aerial pollutants, smoke and $\mathrm{SO}_{2}$, from the Warren Spring Laboratory National Survey (1972) were used if a measure within a 3-mile radius of the collection site was available. Elsewhere, data were supplemented by using measurements obtained from gauges constructed according to the manual issued by the Warren Spring Laboratory. The reflectance (log foot-lamberts) of the bare bark of each of the branches sampled for $M$. unipunctatus was measured with a Salford Electrical Instrument photometer. The proportions (to the nearest 5 per cent) of the upper surfaces of the branch covered respectively by the green alga Pleurococcus, the lichen and the bare bark, were estimated by eye, using a grid placed over the middle $25-\mathrm{cm}$ portion of each branch sampled. The texture of the bark was also measured using an arbitrary scale of 1 (smooth) to 5 (rough surface broken by fissures and protrusions). January and July mean temperature $\left({ }^{\circ} \mathrm{F}\right.$ ) and annual rainfall (inches) were obtained from the Atlas of Britain and Northern Ireland (Anon., 1963) and represent means of daily records over a 30 -year period. Altitude (feet) was obtained from Ordnance Survey maps.

\section{(ii) Method of analysis and statistical results}

The intensity of association between the environmental variables and melanic frequency was analysed using the Statistical Package for the Social Sciences (S.P.S.S.) devised by Nie, Bent and Hull (1970). Two multiple regression equations, one based upon the set of individual variables and one based upon the set of principal components generated from them, were used to summarise the significant relationships.

Results of the stepwise multiple regression of environmental variables (table 1), reflect the importance of lichen and $\mathrm{SO}_{2}$, which are the first two variables to be entered, and which together account for 90.7 per cent of the total variance of melanic frequency. The remaining variables showing significant partial regression coefficients (smoke and January temperature) account for only an extra 1.8 per cent of the variance. The predictive equation is:

$\%$ melanic $=91 \cdot 12-4 \cdot 14 \sqrt{ }$ Lichen cover $+4 \cdot 15 \sqrt{ } \mathrm{SO}_{2}$ $+19.95 \log _{10}$ Smoke -2.40 January temperature. 
TABLE 1

Stepwise multiple regression of melanic frequencies against environmental variables

\begin{tabular}{|c|c|c|c|c|c|c|}
\hline Step & $\begin{array}{c}\text { Variable } \\
\text { (transformation } \\
\text { used) }\end{array}$ & $\begin{array}{l}\text { Cumulative } \\
\text { proportion } \\
\text { of variance } \\
\text { accounted for }\end{array}$ & $\begin{array}{l}\text { Partial } \\
\text { regression } \\
\text { coefficient } \\
\text { (B) }\end{array}$ & $\underset{B}{\text { S.E. of }}$ & F & $\mathbf{P}$ \\
\hline 1 & Lichen $(\sqrt{ })$ & 0.855 & -3.51 & 1.35 & $6 \cdot 73$ & $<0.01$ \\
\hline 2 & $\mathrm{SO}_{2}(\sqrt{ })$ & 0.907 & $3 \cdot 86$ & 1.31 & $8 \cdot 70$ & $<0.01$ \\
\hline 3 & Smoke $\left(\log _{10}\right)$ & 0.917 & $20 \cdot 50$ & $9 \cdot 97$ & $4 \cdot 23$ & $<0.01$ \\
\hline 4 & January temp. & 0.925 & $-2 \cdot 89$ & 1.45 & 3.98 & $<0.01$ \\
\hline 5 & Rainfall & 0.927 & $-0 \cdot 12$ & $0 \cdot 15$ & 0.59 & $>0.05$ \\
\hline 6 & Bare bark $\left(\log _{10}\right)$ & 0.928 & $10 \cdot 70$ & $13 \cdot 46$ & 0.63 & $>0.05$ \\
\hline 7 & Reflectance $\left(\log _{10}\right)$ & 0.929 & -8.88 & $10 \cdot 79$ & $0 \cdot 68$ & $>0.05$ \\
\hline 8 & Bark texture & 0.930 & 0.38 & $1 \cdot 41$ & 0.07 & $>0.05$ \\
\hline
\end{tabular}

Constant $=84 \cdot 78$.

The exclusion of the remaining variables from the equation is due to their high standard errors and low F-values.

The second predictive equation for melanic frequency is based upon principal component analysis and was employed here since two-thirds of the variables are significantly associated with each other. Five major components were extracted from the 11 parameters and together they accounted for 89 per cent of the total variation in the data (table 2). The first component is associated with 51 per cent of the total variation. It is characterised by a high positive loading on lichen cover, and high negative loadings on smoke, $\mathrm{SO}_{2}$ and the amount of bare bark, and seems to represent an industrial component. Component two, associated with 16 per cent of the variation in the data, is probably a climatic one as its main features are moderately high negative loadings on altitude, January and July temperatures, and rainfall. Component three, associated with 10 per cent of the total variation, has a high positive loading on Pleurococcus and a moderate negative loading on bare bark and probably represents some unmeasured feature of the bark which is unaffected by pollution such as the age of the

TABLE 2

Reduction of environmental variables to five independent components by principal component analysis. Circles represent fewest variables providing 50 per cent or more of the total variance for eas, of the components and crosses those variables significant at the 5 per cent level

\begin{tabular}{|c|c|c|c|c|c|}
\hline \multirow[b]{2}{*}{ Variable } & \multicolumn{5}{|c|}{ Components } \\
\hline & 1 & 2 & 3 & 4 & 5 \\
\hline Smoke & $\otimes$ & $x$ & - & - & - \\
\hline $\mathrm{SO}_{2}$ & $\otimes$ & - & - & - & - \\
\hline Reffectance & $x$ & - & - & $(\theta)$ & $\otimes$ \\
\hline Pleurococcus & - & $x$ & $\otimes$ & - & - \\
\hline Lichen & $\otimes$ & $x$ & - & - & $\otimes$ \\
\hline Bare bark & $\otimes$ & - & $\otimes$ & - & $\otimes$ \\
\hline Bark texture & $x$ & $x$ & - & - & - \\
\hline January temp. & $x$ & $\otimes$ & - & - & - \\
\hline July temp. & $x$ & $\otimes$ & - & - & - \\
\hline Rainfall & $x$ & $\otimes$ & - & $\otimes$ & - \\
\hline Altitude & - & $\otimes$ & - & - & - \\
\hline
\end{tabular}


trees sampled. The fourth and fifth components are trivial, each accounting for only 6 per cent of the total variation.

The relative importance of these components in relation to melanic abdominal colour was then analysed by multiple regression. Each component has a specific combination of data at each sampling site and these values were used as variables in the stepwise regression of melanic frequencies on principal components (table 3). The industrial component (1) accounts

TABLE 3

Stepwise multiple regression of melanic abdominal frequencies against five principal components

\begin{tabular}{|c|c|c|c|c|c|c|}
\hline Step & Component & $\begin{array}{l}\text { Cumulative } \\
\text { proportion } \\
\text { of variance } \\
\text { accounted for }\end{array}$ & $\begin{array}{c}\text { Partial } \\
\text { regression } \\
\text { coefficient }(\mathrm{B})\end{array}$ & $\begin{array}{c}\text { S.E. of } \\
\text { B }\end{array}$ & $\mathbf{F}$ & $\mathbf{P}$ \\
\hline 1 & 1 & 0.742 & $11 \cdot 24$ & 1.54 & $53 \cdot 27$ & $<0.01$ \\
\hline 2 & 3 & 0.859 & $8 \cdot 27$ & $1 \cdot 67$ & $24 \cdot 67$ & $<0.01$ \\
\hline 3 & 2 & 0.900 & $-7 \cdot 61$ & $2 \cdot 17$ & $12 \cdot 26$ & $<0.01$ \\
\hline 4 & 5 & 0.906 & $-7 \cdot 13$ & 3.92 & $3 \cdot 31$ & $<0.05$ \\
\hline 5 & 4 & 0.908 & $2 \cdot 94$ & $2 \cdot 84$ & 1.07 & $>0.05$ \\
\hline
\end{tabular}

for most (74.2 per cent) of the total variation in melanic frequency. The second predictive equation, using all components with significant partial regression coefficients, is :

$$
\begin{array}{r}
\% \text { melanic }=44.81+11.23 \text { Component } 1+8 \cdot 60 \text { Component } 3 \\
-6.69 \text { Component } 2-4.79 \text { Component } 5
\end{array}
$$

and accounts for 90.6 per cent of the total variation.

\section{(iii) Biological interpretations}

The regression of principal components points to three complexes, namely industry, bark and climate, in this order of importance, as being of significance in maintaining the abdominal colour dimorphism of $M$. unipunctatus. With regard to industry, the order of inclusion of lichen, $\mathrm{SO}_{2}$ and smoke in the multiple regression of environmental variables (table 1 ), suggests that lichen is detrimental to the crypsis of melanics and is of greater importance than either the blackening of the bark by smoke or any direct toxic effect of the two pollutants. The bark complex, accounts for a further 11.7 per cent of the variation in melanic frequency that is independent of the industrial element (table 3). It thus supports the view that visual selection is of importance and suggests that factors inherent to the substratum on which the insects live are of greater importance than climatic components in accounting for the variation in melanic frequency. With regard to climate, the regression of environmental variables (table 1) indicates that temperature, in so far as it is not completely correlated with $\mathrm{SO}_{2}$, smoke or another as yet unidentified factor, influences melanic frequencies. Consequently, it was considered pertinent to test both visual predator and temperature selection of colour morphs. 


\section{VISUAL PREDATOR SELEGTION}

To detect whether predation, in particular a differential one, occurs, two series of experiments were attempted: preliminary selection experiments in an aviary; and mark release recapture experiments in urban and rural plantations of European larch (Larix decidua Mill.).

\section{(i) Aviary experiments}

Two adult females, one dark and one light, were released on each of three urban and three rural larch branches in an indoor aviary, containing three pairs of hand-reared great tits (Parus major L.), which had been deprived of food for 2 hours before testing. At the end of each test, all surviving psocids were removed from the branches and the number taken recorded.

TABLE 4

Numbers of dark and light M. unipunctatus exposed to and taken by six great tits on urban and rural larch in an aviary

\begin{tabular}{|c|c|c|c|c|c|c|c|c|c|}
\hline $\begin{array}{c}\text { Day of } \\
\text { trial }\end{array}$ & $\begin{array}{c}\text { No. of } \\
\text { trials }\end{array}$ & \multicolumn{2}{|c|}{$\begin{array}{c}\begin{array}{c}\text { Dark insects } \\
\text { on urban larch }\end{array}\end{array}$} & \multicolumn{2}{|c|}{$\begin{array}{l}\text { Light insects } \\
\text { on urban larch }\end{array}$} & \multicolumn{2}{|c|}{$\begin{array}{c}\begin{array}{c}\text { Dark insects } \\
\text { on rural larch }\end{array} \\
.\end{array}$} & \multicolumn{2}{|c|}{$\begin{array}{l}\text { Light insects } \\
\text { on rural larch }\end{array}$} \\
\hline $\begin{array}{c}8 / 7 / 75 \\
9 / 7 / 75 \\
10 / 7 / 75\end{array}$ & $\begin{array}{l}5 \\
5 \\
5\end{array}$ & $\begin{array}{l}15 \\
15 \\
15\end{array}$ & $\begin{array}{l}9 \\
7 \\
9\end{array}$ & $\begin{array}{l}15 \\
15 \\
15\end{array}$ & $\begin{array}{r}6 \\
9 \\
10\end{array}$ & $\begin{array}{l}15 \\
15 \\
15\end{array}$ & $\begin{array}{l}8 \\
5 \\
5\end{array}$ & $\begin{array}{l}15 \\
15 \\
15\end{array}$ & $\begin{array}{l}1 \\
5 \\
3\end{array}$ \\
\hline Total: & & & 25 & & 25 & & 18 & & 9 \\
\hline
\end{tabular}

Results summarised in table 4, show three main features. Firstly, predation of $M$. unipunctatus does occur since 77 of the 180 insects released were taken by the great tits. Secondly, predation is different on the two kinds of branches. A three-way analysis of variance indicates that significantly more insects of both morphs were taken on urban (50) than on rural (27) larch $\left(\mathrm{F}_{1}, 48=6.25,0.01<\mathrm{P}<0.05\right)$ so that the mosaic patterning of the epiphytes on rural larch appears to provide greater crypsis for both morphs. Finally, birds on rural larch predate the two colour forms differentially with regard to their cryptic efficiency since more dark (18) than light (9) insects are taken on rural larch. This difference, although noticeable, is not statistically significant due to the high heterogeneity among trials.

\section{(ii) Mark release recapture experiments}

To determine whether or not differential predation occurs in the natural situation, a series of mark release recapture experiments were carried out in July 1975 at an urban (Templenewsam, Leeds) and at a rural (Ampleforth, North York Moors) larch plantation. Within each plantation, a total of 200 (100 light and 100 dark) healthy females collected from Lindley, Yorkshire and marked with paint on the ventral side of the abdomen, a different colour being used on each day, were released over a period of 10 days into an isolated block of about 100 larch trees with interlacing branches. Wingless adult females were thus able to move through, but not out of, these blocks. In both blocks, a pair of marked insects, one dark and 
one light, were released at dusk on each of 20 larch branches and this procedure was repeated every 2 days on five consecutive occasions. On the $1 \mathrm{lth}$ day, all the trees at both plantations were sampled by beating as many branches as possible with a walking stick. All insects dislodged were collected by a suction tube.

Results (table 5), although not statistically significant, suggest the occurrence of differential survival since at the urban site more dark (19) than light (14) insects were recaptured and at the rural site the reverse occurred, i.e. more light (11) than dark (8) were recaptured. This is consistent with the view that in both areas the more cryptic form is advantageous

TABLE 5

Results of the mark release recapture experiments

\begin{tabular}{|c|c|c|c|c|c|c|}
\hline \multirow[b]{2}{*}{ Location } & \multirow[b]{2}{*}{$\begin{array}{l}\text { Date of } \\
\text { release }\end{array}$} & \multicolumn{2}{|c|}{ Number of dark insects } & \multicolumn{2}{|c|}{ Number of light insects } & \multirow[b]{2}{*}{$\begin{array}{l}\text { Total insects } \\
\text { captured }\end{array}$} \\
\hline & & released & $\begin{array}{c}\text { recaptured on } \\
22 / 7\end{array}$ & released & $\begin{array}{c}\text { recaptured on } \\
22 / 7\end{array}$ & \\
\hline \multicolumn{7}{|l|}{ Templenewsam } \\
\hline & $12 / 7$ & 20 & 0 & 20 & 0 & \\
\hline & $14 / 7$ & 20 & 2 & 20 & 1 & \\
\hline & $16 / 7$ & 20 & 3 & 20 & 3 & \\
\hline & $18 / 7$ & 20 & 5 & 20 & 3 & \\
\hline & $20 / 7$ & 20 & 9 & 20 & 7 & \\
\hline & & & (19) & & (14) & 741 \\
\hline \multirow[t]{7}{*}{ Ampleforth } & & & $23 / 7$ & & $23 / 7$ & \\
\hline & $13 / 7$ & 20 & 0 & 20 & 0 & \\
\hline & $15 / 7$ & 20 & 0 & 20 & 1 & \\
\hline & $17 / 7$ & 20 & 2 & 20 & 2 & \\
\hline & $19 / 7$ & 20 & 2 & 20 & 3 & \\
\hline & $21 / 7$ & 20 & 4 & 20 & 5 & \\
\hline & & & (8) & & (11) & 1127 \\
\hline
\end{tabular}

as only very small selection pressures need be involved in producing the observed colour polymorphism (Cain, 1965; Lewontin, 1974).

\section{Temperature Selection}

Temperature is of paramount importance in determining the developmental rate of an insect and in the field, dark morphs may well absorb more solar radiation and consequently develop faster than light ones do. To test this suggestion, the developmental rates of dark and light morphs were compared from measures of reproductive organ sizes and female body weight, using insects collected on the same day at four localities along a north-easterly gradient from Templenewsam to Ampleforth. The sampling day in early July was chosen to coincide with both the peak adult flight period in the male and the later stages of the preoviposition period in the female as, during the oviposition period, large variations in female body weight occur so that significant differences between morphs are harder to detect. Within any species of insect, the size of the reproductive system is usually considered to be related to the developmental stage of the individual and measurements of ovariole, egg and spermatophore length were made by 
simple dissection in 0.7 per cent sodium chloride. The mean dry weight of females, after drying for 7 days at $55^{\circ} \mathrm{C}$, was also recorded.

No significant differences in length of the reproductive organs were found between morphs at any of the four localities. However, at all sites, dark females were heavier than light ones (table 6). This difference in dry body weight was significant only at Harlow Car

$$
\left(t_{23}=3.50,0.001<\mathrm{P}<0.002\right)
$$

where adult females were both heavier and had larger ovarioles and eggs than adult females at the other three localities. $M$. unipunctatus female body weight rises slowly during the l-week preoviposition period after which time they lay their eggs in batches over a 1- to 2-week period and their weight falls sharply (Wapshere, 1960). Thus it may be that differences in body weight of dark and light morphs may reflect a faster rate of development of

\section{TABLE 6}

Comparisons of the mean dry body weight of dark and light adult females at four localities in Yorkshire

$\begin{array}{lcc}\text { Locality } & \text { Morph colour } & \begin{array}{c}\text { Dry body weight }\left(10^{-5} \mathrm{~g}\right) \\ \pm \mathrm{S} . \mathrm{E} \cdot(\mathrm{n})\end{array} \\ \text { Templenewsam } & \text { Dark } & 75 \cdot 11 \pm 6 \cdot 63(14) \\ & \text { Light } & 63 \cdot 60 \pm 8 \cdot 11(3) \\ \text { Lindley } & \text { Dark } & 117 \cdot 07 \pm 5 \cdot 02(19) \\ & \text { Light } & 107 \cdot 11 \pm 4 \cdot 17(17) \\ \text { Harlow Car } & \text { Dark } & 138 \cdot 50 \pm 4 \cdot 12(14) \\ & \text { Light } & 117 \cdot 96 \pm 4 \cdot 69(11) \\ \text { Ampleforth } & \text { Dark } & 111 \cdot 20 \pm 4 \cdot 86(5) \\ & \text { Light } & 109 \cdot 24 \pm 3.88(20)\end{array}$

dark than of light females during this period as the insect increases in size and surface area thus allowing a more differential absorption of heat. If this is so, dark morphs may well have a selective advantage over light ones particularly at low insolation.

It is difficult, however, in Yorkshire, to determine whether melanics are favoured in areas of low insolation since the most heavily industrialised and polluted areas here are generally situated in the least sunny regions so that the effect of industry and sunshine are hard to separate. Industry appears to be more important since in those few areas where both pollution and sunshine levels (obtained from the Atlas of Britain and Northern Ireland, Anon., 1963) are high, melanics are common, while the reverse also holds, i.e. melanics are rare in areas where pollution and sunshine levels are low. Nevertheless, sunshine does appear to be of importance in those areas where pollution levels are intermediate since at all but one locality sampled, where pollution levels are intermediate and sunshine levels are less than average $(\bar{X}=1208 \mathrm{~h})$, melanic frequencies are greater than average $(\bar{X}=48.4$ per cent). Both these averages were derived using data from all 42 localities sampled. Hence, in these intermediate areas, where high background heterogeneity must ensure the availability of suitable resting sites for both colour morphs, such climatic selection may be of greater importance than visual selection. 


\section{Discussion}

The abdominal colour dimorphism of $M$. unipunctatus appears to be relatively stable in Yorkshire at present since no significant trends in melanic frequency are evident at any of the localities sampled over 3 years (table 7) and this may well reflect the stabilisation of pollution levels since 1970 in these areas (Warren Spring Laboratory). The present work indicates that the main selective force involved in maintaining this stable state is visual selection by predators for crypsis and that, in addition, climatic selection may also operate differentially upon the two morphs. However, the precise system by which the observed morph-ratio cline of $M$. unipunctatus is maintained remains to be discovered.

The simplest system to imagine, since $M$. unipunctatus individuals are small and widely distributed over the entire tree, is one in which there are more dark and light backgrounds than dark and light individuals of $M$.

TABLE 7

Frequency of melanic M. unipunctatus collected in Torkshire over a 3-year period. Total number collected is given in brackets

$\begin{array}{lcc}\text { Locality } & \text { Year } & \text { Melanic frequency (\%) } \\ \text { Hawes } & 1973 & 3 \cdot 2 \pm 1 \cdot 1(250) \\ & 1974 & 1 \cdot 5 \pm 1 \cdot 5(65) \\ \text { Harewood 2 } & 1975 & 3 \cdot 0 \pm 3 \cdot 0(33) \\ & 1973 & 67 \cdot 0 \pm 3 \cdot 5(185) \\ \text { Templenewsam } & 1974 & 73 \cdot 0 \pm 7 \cdot 3(37) \\ & 1975 & 68 \cdot 2 \pm 3 \cdot 8(154) \\ & 1973 & 75 \cdot 0 \pm 9 \cdot 7(20) \\ & 1974 & 77 \cdot 4 \pm 4 \cdot 6(84) \\ & 1975 & 78 \cdot 2 \pm 4 \cdot 1(101)\end{array}$

unipunctatus. Given this abundance of appropriate resting sites, then, in urban areas, where dark coloured backgrounds predominate, light morphs will be at a cryptic disadvantage more often than the dark ones. In such a situation, visual predation will completely eliminate the light form unless (1) the smaller number of light than of dark $M$. unipunctatus prevents the formation of a searching image by the birds for the light forms; (2) there is sufficient migration of light insects into such areas; or (3) opposing selective forces operate which ensure that two or more alleles of one gene are maintained in the population. The same argument holds for dark insects in rural areas. In intermediate areas, however, where the proportion of dark and light backgrounds approaches equality, disruptive predator selection alone may maintain the colour morphs. There is no evidence available relating to (1) or (2). There is, however, some evidence that climatic as well as visual selection is acting on the alleles controlling abdominal colour in $M$. unipunctatus and that this may produce a morph-ratio different from that determined by visual predation alone.

More, however, needs to be known about the precise action of such physiological selection. Ford (1971) noted that many stable polymorphisms are probably maintained by physiological heterozygous advantage and stressed that this indeed tends to be evolved in any polymorphism. Although 
the action of heterosis is undoubted in the case of the sickle-cell locus in humans (Allison, 1956), very likely in the case of Cepaea (Cain and Currey, 1963 ; 1968), and probable in the case of Biston betularia (L.) (Clarke and Sheppard, 1966; Lees and Creed, 1975; Steward, 1977), its existence in M. unipunctatus has not been demonstrated. It may, nevertheless, occur since the greater weight of dark than of light females in the field may reflect a fitness advantage of dark heterozygotes over both light and dark homozygotes. It should also be noted that since industrial melanism has taken place with such rapidity, pleiotropic effects may still be evolving and for this reason are not easily detectable.

Visual predator selection alone, however, may maintain the colour polymorphism in $M$. unipunctatus provided that there is competition among these insects for appropriate resting sites. This is because either morph will be favoured when it is rare and occupies only its optimum background but will be at a relative disadvantage when it is so common as to overflow on to backgrounds favouring the alternative morph. Provided that the total population size remains constant, such selection may strictly be described as frequency-dependent, but since in most cases this fluctuates, it is also density-dependent. A mechanism of this kind has recently been proposed by Bishop and Cook (1975) as a possible alternative to heterozygous advantage in the maintenance of the industrial polymorphism in moths. It could also be at work among populations of $M$. unipunctatus for two reasons. Firstly, $M$. unipunctatus is one of the most abundant woodland species and its populations are dense. Secondly, the resting sites actually available to the animal must be far fewer than those apparently available because of disturbance resulting from the movement of the branches by wind, and by birds and from other arthropods, of which there are many, walking about on these branches.

Both these hypotheses of stability are testable only by further ecological study.

Acknowledgements.-It is a pleasure to acknowledge the help and advice given during the course of this work by my two supervisors Dr E. Broadhead and Dr B. Shorrocks. I am also grateful to Dr M. R. D. Seaward (Department of Environmental Science, Bradford University) for his advice concerning the measurement of pollution; and to Dr J. R. Krebs (Edward Grey Institute, Oxford) for the use of aviary facilities. This work was supported by a Leeds University Research Grant.

\section{REFERENGES}

ALlison, A. C. 1956. The sickle-cell and haemoglobin C genes in some African populations. Ann. Hum. Genet., 21, 67-89.

ANON. 1963. The Atlas of Britain and Northern Ireland (planned and directed by D. P. Bickmore and M. A. Shaw). Clarendon Press, Oxford.

BISHOP, J. A., AND CoOK, L. M. 1975. Moths, melanism and clean air. Scient. Am., 232, 90-99.

BROADHEAD, E. 1958. The psocid fauna of larch trees in northern England-an ecological study of mixed species populations exploiting a common resource. 7. Anim. Ecol., 27, 217-263.

CAIN, A. J. 1965. Recent population studies on Cepaea at Oxford. Proc. First Europ. Malac. Congr., London 1962, 209-213.

Cain, A. J., ANd currey, J. D. 1963. Area effects in Cepaea. Phil. Trans. Roy. Soc. Lond., B., $246,1-81$.

$42 / 2-\mathrm{B}$ 
CAIN, A. J., AND CURREY, J. D. 1968. Climate and selection of banding morphs in Cepaea from the climate optimum to the present day. Phil. Trans. Roy. Soc. Lond., B., 253, 483-498.

CLARKE, C. A., AND SHEPPARD, P. M. 1966. A local survey of the distribution of industrial melanic forms of the moth Biston betularia and estimates of the selective value of these in an industrial environment. Proc. R. Soc., B, 165, 424-439.

FORD, E. B. 1971. Ecological Genetics. Chapman and Hall, London.

LEES, D. R., AND CREED, E. R. 1975. Industrial melanism in Biston betularia: the rôle of selective predation. 7. Anim. Ecol., 44, 67-83.

Lewontin, R. C. 1974. The Genetic Basis of Evolutionary Change. Columbia University Press, New York and London.

Nie, N. H., Bent, D. H., AND HULl, C. H. 1970. Statistical Package for the Social Sciences. McGraw-Hill, New York.

POPESCU, C., BROADHEAD, E., AND SHORROCKS, B. 1978. Industrial melanism in Mesopsocus unipunctatus (Müll.) (Insecta : Psocoptera) in northern England. Ecological Entomology, 3, 209-219.

STEWARD, R. c. 1977. Melanism and selective predation in three species of moths. 7 . Anim. Ecol., 46, 483-496.

WAPSHERE, A. J. 1960. Studies of Psocid Ecology in Larch Plantations. D.Phil. thesis, University Library, Leeds.

WARREn SPRING Laboratory. 1972. The Investigation of Air Pollution. Annual Summary, April 1972-March 1973. 